\title{
南極昭和基地超伝導重力計の遠隔地監視
}

\author{
池田 博 ${ }^{\dagger}$, 土井 浩一郎*1, 松島 洋輔*2, \\ 岸田 太*2, 飯村 憲*2, 渋谷 和雄*1
}

\section{Monitoring System for the Superconducting Gravimeter at the Syowa Station, Antarctica}

\author{
Hiroshi IKEDA $^{\dagger}$, Koichiro DOI*1, Yosuke MATUSHIMA*2, Futoshi KISHIDA*2, \\ Ken IIMURA ${ }^{* 2}$ and Kazuo SHIBUYA*1
}

\begin{abstract}
Synopsis: A communications satellite (INTELSAT) data receiving system with a 7.6m-diameter parabolic antenna was installed at Syowa Station in February 2004. We have carried out communications with the Antarctica station using a virtual private network (VPN) employing a S-Box. We began operation of a real-time monitoring system from Japan on August 26, 2004. The earthquake that recently occurred in Sumatra, Indonesia was observed from Japan using the superconducting gravimeter at Syowa Station.
\end{abstract}

Keywords: superconducting gravimeter, Intelsat, monitoring system, Antarctica

\section{1. はじめに}

南極昭和基地では 1993 年 3 月から世界に先駆けて超伝導 重力計による重力変化の連続観測を開始し 2005 年 4 月現在 も南極大陸で唯一の超伝導重力計として観測を継続してい $3^{1)}$ 。第 44 次南極地域観測隊地学担当が設置した 4K-GM 冷凍機付き超伝導重力計（CT043）は2003 年 2 月から立上 げを開始し 3 月 18 日に初期レビテーションに成功し、4月 18 日よりデータの収録を開始した。11月まで初代の $10 \mathrm{~K}-\mathrm{GM}$ 冷凍機付き超伝導重力計との並行観測を行い、 2003 年 11 月 6 日より CT043 単独での観測がスタートした。 第 45 次隊が到着してから設置場所の移設とフレームの改 良を行い、第 45 次隊夏隊の持込んだ絶対重力計によって重 力值の絶対值校正を行った ${ }^{2)}$ 。その後、新超伝導重力計は 現在まで順調に稼動しており、2005 年 1 月には4K-GM 冷

Received May 2, 2005

筑波大学研究基盤総合センター低温部門

干305-8577 茨城県つくば市天王台 1-1-1

Cryogenic Division Research Facility Center University of

Tsukuba, 1-1-1 Tenoudai, Tsukuba-shi, Ibaraki 305-8577, Japan

*1 国立極地研究所

干173-8515 東京都板橋区加賀 1 丁目 9-10

National Institute of Polar Research, 9-10, Kaga 1-chome,

Itabashi-ku, Tokyo 173-8515, Japan

*2 大陽日酸素株式会社

干142-8558 東京都品川区小山 1-3-26 東洋 Bldg.

Taiyo Nippon Sanso Corporation, Toyo Bidg. 1-3-26 Koyama

Shinagawa-ku, Tokyo 142-8558, Japan

† E-mail:ikeda@bk.tsukuba.ac.jp
凍機の交換作業を行い第 45 次越冬隊隊員から第 46 次越冬 隊員に引継ぎ現在も順調に稼動している。

本報告では、南極昭和基地で稼動している新超伝導重力 計の運転状況をリアルタイムで監視できるシステムの構築 に成功したので報告する。本稿では南極昭和基地に設置し てある超伝導重力計のデータと Web カメラにより装置お よび冷凍機・圧縮機運転音を人工衛星とインターネットを 利用して日本から直接監視するシステムの開発について報 告する。

\section{2. 南極昭和基地との通信方法}

南極昭和基地という設置場所の特異性から、著者が越冬 していた第 44 次観測隊までは国内と南極昭和基地の交信 はインマルサット衛星による通信で $64 \mathrm{kbps}$ の速度のため 3 時間に 1 度の通信のみ可能であった。また、電子メール のサービスのみでインターネットへの接続はできなかっ た。しかし、第 45 次観測隊によりインテルサット衛星に送 受信出来るレドームに入った直径 $7.6 \mathrm{~m}$ のアンテナが設置 されたことにより Fig. 1 にあるように昭和基地のアンテナ から発信された通信電波はインド洋上のインテルサット衛 星を介して日本の山口にある地球局で受信され、さらに極 地研究所へ配信され,さらにインターネットによって筑波 大学で送受信できるようになった。通信速度は今までより も飛躍的に改善され $1 \mathrm{Mbps}$ の通信速度が可能となり常時 接続も可能となった。

そこで Fig. 2 に示すように昭和基地に設置してある超伝 
導重力計の運転状態や観測データを日本から直接監視でき るようなネットワークコンピュータを著者が越冬した第 44 次越冬隊で昭和基地に持ち込み、新超伝導重力計装置立 上げ時に通信可能なように組み込んだ ${ }^{2)}$ 。越冬終了後、帰 国してから筑波大学から IP (Internet protocol）申請した。 極地研究所を介して南極昭和基地重力計室の計測用パソコ ンとコントローラに対してそれぞれ専用 IP を取得し、筑波 大学においてもモニター用のパソコンの専用 IP を取得し た。また、極地研究所から指定された S-Box（チェック・ ポイント社が中小規模のネットワーク向けに提供する本格 的なファイアウォール専用機）を利用して VPN（Virtual Private Network）による通信によってデータは暗号化され セキュリティー対策を行った。その結果、我々が開発した コントローラの $\mathrm{EzMPICS}^{3)}$ を介して日本から南極昭和基 地の重力計室で稼動している新超伝導重力計に 2004 年 8 月 26 日に直接アクセス出来るようになった。また、2004 年 9 月からは Web カメラ(パナソニック BB-HCM310)によ って装置および冷凍機・圧縮機の運転状況や運転音が直接 遠方監視出来るようになった。

\section{EzMPICS および性能緒言}

EzMPICS はへリウム液化・冷凍機用に開発されたコント ローラで制御速度は 100 1000 msec の設定が可能である。 EzMPICS の CPU はインテル社製 Strong ARM を使用し 32 ビット RISC マイクロプロセッサーで低コスト、高性能、 低消費電力である。OS(オペレーティングシステム)はリア ルタイム OS で実績のあるVxWorks を採用している。 VxWorks は1987 年に米国 Wind River Systems がリリースし たもので TCP/IP ネットワーキング機能を搭載したリアル タイム OS である。システムの仕様としてはオープンシス テムを採用し、入出力点数はアナログ入力 32 点アナログ出 力 16 点デジタル入力 24 点デジタル出力 24 点を取り扱うこ とが可能である。制御方法として ON/OFF 制御、PID 制御、 カスケード制御などを組み合わせることにより自動化プロ グラムを構築する事ができる。EzMPICS が持つ内部データ はネットワークを介して運転操作用パソコンで表示する。

つまり、ネットワーク接続による遠隔地からの低温機器 制御監視およびユーザー作成プログラムによる低温機器の 制御系構築に最適である。ソフトウェア構成図を Fig. 3 に 示すが制御器の寸法は $90 \times 150 \times 180 \mathrm{~mm}$ とコンパクトで女 るが、機能としては低温機器のコントロール機能を凝縮し ており、例えば低温用温度計の出力電圧から変換演算ユニ ットを利用して温度表示などが手軽にできる。

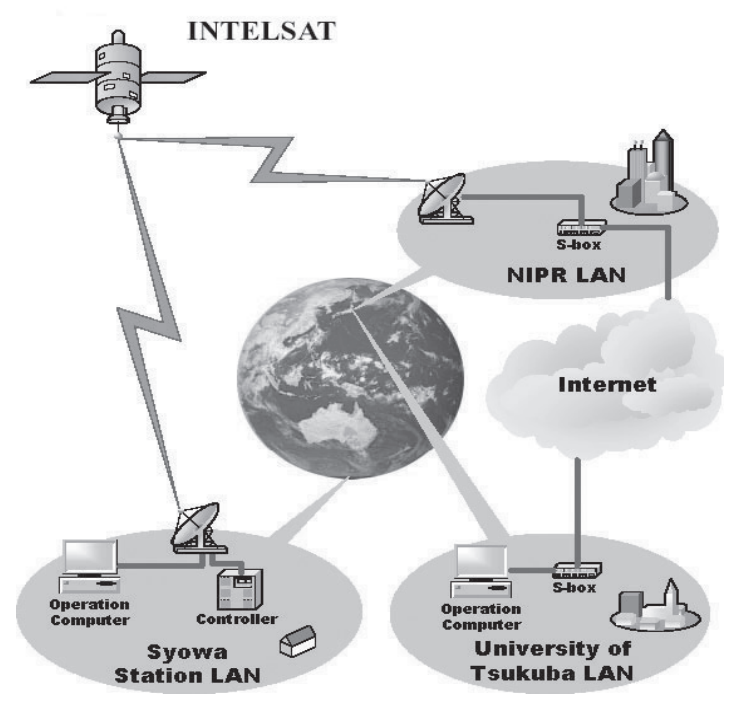

Fig. 1 Monitoring system at Syowa Station, Antarctica.

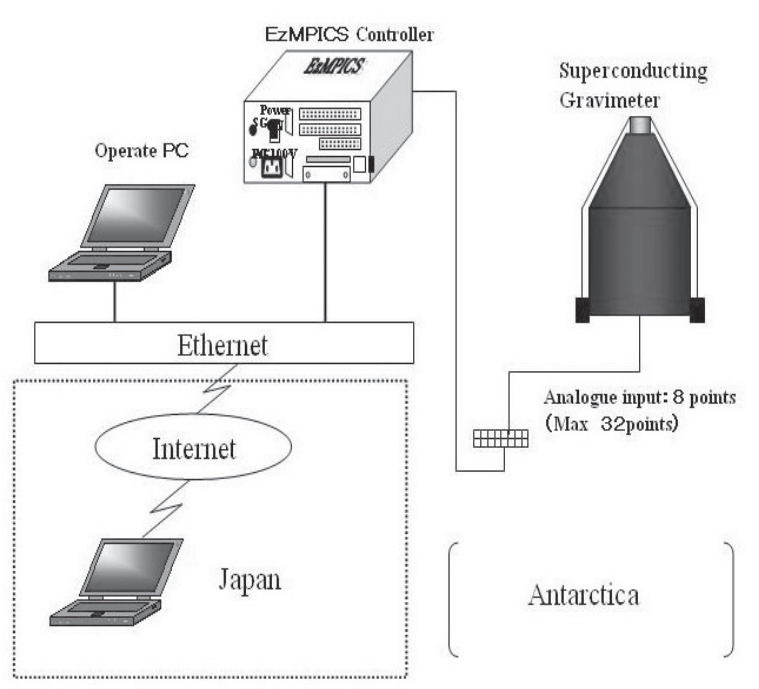

Fig. 2 EzMPICS controller system and remote computer operation.

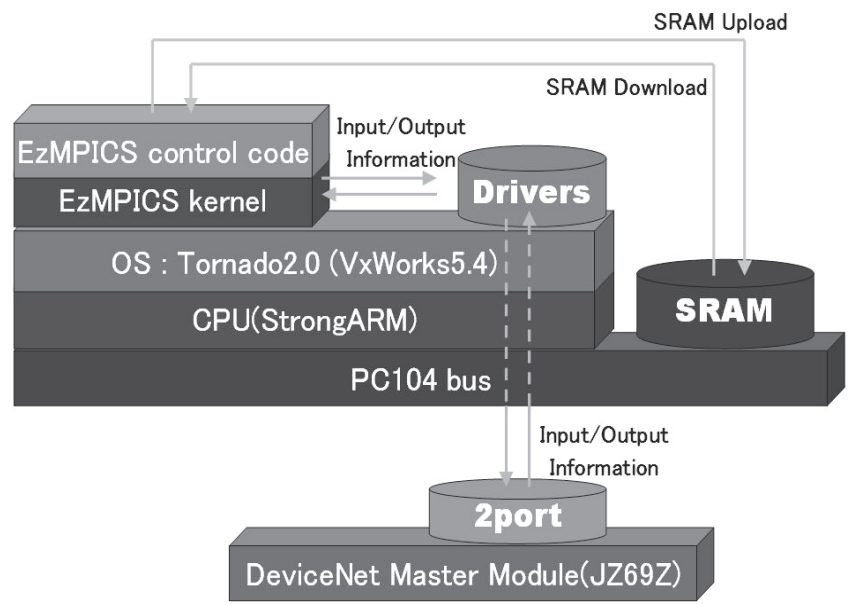

Fig. 3 EzMPICS controller software component. 


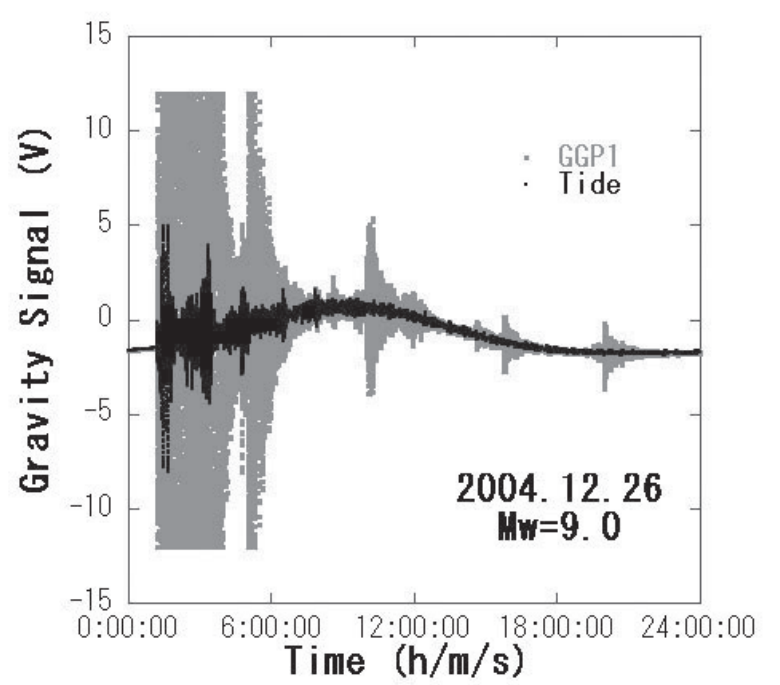

Fig. 4 Real-time remote monitoring system from Japan. Earthquake that recently occurred in Sumatra, Indonesia.

\section{4. 昭和基地からのリアルタイムモニター図}

Fig. 4に示したのは筑波大学において南極昭和基地の新 重力計の観測データをリアルタイムに監視しているグラフ である。2004年12月26日にイドネシアのスマトラ沖に発生 した巨大地震を南極昭和基地で観測した新超伝導重力計の 観測データである。Tideは潮汐を示しており、GGP1はGGP (Global Geodynamics Project) の定めたフールターを使用 して測定間隔が 1 秒間でサンプリングしたデータである。 この地震は巨大地震でありマグニチュード $(\mathrm{Mw}=9.0)$ と発 表されたが、重力計の信号としてはTideとGGP1信号が周期 的に大きく振幅しており地球自由振動という地球物理学的 な現象が時系列的に直接観測されるほど大きな地震であっ たことが読み取れる。この他に観測データだけではなく 4K-GM冷凍機によるへリウム容器内の温度分布も監視す ることができる。そのため日本から南極で越冬している隊 員に冷凍機の状態を日本で専門化が監視して異常があった 場合は知らせることも可能である。2005年1月には4K-GM 冷凍機の交換作業を遠隔監視とWebカメラを利用して第45 次越冬隊員から第46次越冬隊員への引継ぎ作業が日本にい る越冬経験者も交えて南極昭和基地と日本直接交信しなが らスムーズに行うことが出来た。今後は長期的な信頼性を 調査する予定である。

\section{5. まとめ}

南極昭和基地重力計室で立ち上げた超伝導重力計の運転 状況を日本からの直接監視するためにセキュリティーの申 請と専用 IP を取得後、超伝導重力計に取付けた EzMPICS
を介してインド洋上のインテルサット衛星を利用してイン ターネット経由で南極と日本を直接接続することが出来 た。これにより日本からリアルタイムで超伝導重力計の運 転状況の把握ができ、収録データや冷凍機の温度分布など が監視でき日本から南極で越冬している隊員に適切なアド バイスが可能となり担当隊員の負担が軽減されている。

最後に本報告は第 44 次南極地域観測隊皆様に協力を得 て行われました。ここに改めて感謝申し上げます。

\section{参 考 文 献}

1) H. Ikeda, K. doi, Y. Fukuda, T. Noguchi, Y. Tamura, T. Nakashima, K. Iimura and K. Shibuya: "Installation of the superconducting gravimeter in the Syowa Station, Antarctica," Abstract of CSJ Conference 70 (2004) 141 (in Japanese)

池田 博、土井浩一郎、福田洋一、野口隆志、田村良明、中 嶋俊哉、飯村 憲、渋谷和雄: 「南極昭和基地における超伝導 重力計の設置」、第 70 回 2004 年度春季低温工学・超電導学会 講演概要集 (2004) 141

2) H. Ikeda, K. doi, Y. Fukuda, T. Noguchi, Y. Tamura, T. Nakashima, K. Iimura and K. Shibuya:"Installation of superconducting gravimeter in Antarctica and development of its vibration-isolating mechanism and remote monitoring system," TEION KOGAKU 39 (2004) 348-353 (in Japanese)

池田博、土井浩一郎、福田洋一、野口隆志、中嶋俊哉、飯 村 憲, 渋谷 和 :「南極における超伝導重力計の設置とそ の除震及び監視技術の開発」、低温工学 39 (2004) 348-353

3) K. Iimura and T. Nakashima: "Development of process control system by Windows/PC and VME," IEEJ. IIC-99-43 (1999) 69-73.

池田 博 1953 年 6 月生. 1976 年千葉工業大学電気工学科卒業. 1992 年筑波大学院理工学研究科修士課程修了. 1977 年より筑波大 学低温センター技官を経て、1994 年より物理工学系講師、2002 年 加第 44 次南極地域観測隊員. 現在、筑波大学大学院数理物理研 究科講師. 主に高温超伝導体の低温物性、酸化物蓄冷材の開発、低 温技術の開発に従事. 低温工学協会会員. 工学博士.

土井 浩一郎 1960 年 6 月生. 1984 年京都大学理学部卒業. 1991 年京都大学大学院理学研究科博士課程修了. 1991 年科学技術庁科 学技術特別研究員. 1995 年より国立極地研究所に勤務. 主に超伝 導重力計を利用した南極域における重力の時間変化の研究に従 事. 日本測地学会会員. 理学博士.

松島 洋輔 1977 年 11 月生、2000 年広島大学理学部卒業、2000 年広島大学理学研究科修士課程修了、2002 年日本酸素株式会社開 発・エンジニアリング本部計測・制御センター勤務、主にプラント 制御システム開発に従事、リアルタイムシミュレーション技術を応 用したプラント傾向監視を担当.

岸田太 1965 年 12 月生、1988 年長崎総合科学大学工学部卒業、 1988 年（株）日酸エドワーズ勤務、1990 年日本酸素株式会社開発・ エンジニアリング本部計測・制御センター勤務、主にプラント制御 システム開発に従事、ネットワーク技術を利用した制御システムの 開発およびシステム構築を担当. 
飯村 憲 1950 年 5 月生. 1974 年上智大学理工学部機械工学科 卒業. 1976 年上智大学大学院理工学研究科機械工学修士課程修了. 1976 年 (株) 三菱 TRW 勤務、1990 年日本酸素株式会社開発・エン ジニアリング本部計測・制御センター勤務. 主にプラント制御シス テム開発に従事. 計測自動制御学会員.
渋谷 和雄 1948 年 5 月生. 1972 年東京大学理学部地球物理学 科卒業. 1978 年東京大学理系大学院地球物理学専攻博士課程修了. 1978 年国立極地研究所助手. 1994 年より同研究所・教授、現在に 至る. 一貫して南極地学研究に従事. 日本測地学会、日本地震学会 会員. 理学博士. 